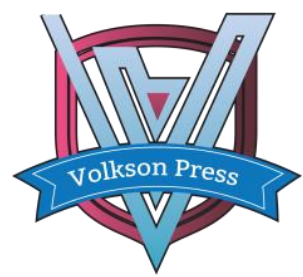

Contents List available at VOLKSON PRESS

\title{
Evaluation on Competitiveness of Cultural Creative Industry Based on Catastrophe Progression Method
}

\author{
Ping Gu1, Cheng Chen2, *and Zili Chen3 \\ 1,2,3School of Economics and Management, Jiangsu University of Science and Technology, Zhenjiang, P.R. China \\ *m18852890027@163.com
}

This is an open access article distributed under the Creative Commons Attribution License, which permits unrestricted use, distribution, and reproduction in any medium, provided the original work is properly cited.

\section{ARTICLE DETAILS}

\section{Article History:}

\section{Received 02 october 2017}

Accepted 06 october 2017

Available online 11 october 2017

\section{Keywords:}

Catastrophe progression method,

Cultural creative industry, Competitiveness..

\section{ABSTRACT}

According to the characteristics of the connotation of cultural creative industry and the theory of competitiveness, competitiveness evaluation index system of regional cultural creative industry is established by catastrophe progression method, selecting 11 provinces and cities in east China, meanwhile, taking cultural creative industry as the research subject in these areas, the paper carries out quantitative study with evaluation on whole industrial competitiveness. Then, it gives a comprehensive analysis on the evaluation result and points out existing problems in cultural creative industry in different provinces and cities, as well as promotion strategies.

\section{Introduction}

Since the 21st century, with the aggravation of the economic globalization, and the transformation of economic growing mode, cultural creative industry has become a sunrise industry which has the most commercial value and cultural connotation in this era. At the same time, in the current context of supply-side structural reform in our country, the cultural creativity industry has absolute advantages in industry amalgamation, innovation, added value of high-tech, and low power consumption innovative when compared with other traditional industries. Therefore, the development of cultural creative industry, and the promotion of the competitiveness are the key to realize the optimization and upgrading of industrial structure.

Compared with other developed countries, cultural creative industry started relatively late in our country, and there are unbalanced development in different district. But overall, cultural creativity industry has been on some scale in east China. This paper through catastrophe progression method to construct competitiveness evaluation model of cultural creative industry, and selected 11 provinces and cities in east China, including Beijing, Tianjin, Hebei, Liaoning, Shandong, Shanghai, Jiangsu, Zhejiang, Fujian, Guangdong, and Hainan. Based on the cross section data of 2014,it utilized quantitative evaluation in these areas. Then, according to the result of competitiveness evaluation, this paper put forward some useful countermeasures to promote comparative advantages in different regions. Meanwhile it provide a reference for relevant government departments to make policy, so that fully enhance the competitiveness of cultural creative industry in our country.

\section{Literature References}

It is a new research direction when we use competitiveness theory in cultural creative industry. Many existing studies through the perspective of competitiveness definition to research cultural creative industry competitiveness[1]. Hua (2005) thought Competitiveness is divided into three levels, including microcosmic, middle and macrocosmic, and the competitiveness of cultural industry belongs to middle level[2].Gu and Xia (2007) considered that the competitiveness of cultural industry includes realistic and potential competitiveness[3]. In the aspect of evaluation method, Ye and Li (2009) built a competitiveness evaluation index system which reflects reality and potential competitiveness, and they used factor analysis and cluster analysis in the evaluation[4].In the view of empirical research[5-7], some scholars established evaluation system on the basis of related research, then used the AHP to give weights and through relevant data to carry out empirical analysis in different provinces and cities(He,2011;Gao and Shao,2013;Kang and Chen,2014).And Zhao et al (2014) used Delphi method to confirm the weight of each index in the evaluation system[8].

In conclusion, there are many methods can be used in the competitiveness evaluation, such as factor analysis, AHP and Delphi, etc. Compared with these methods, catastrophe progression method does not need to determine the index weight, and it only consider the relative important degree among different indexes, so that reduce the subjective influence throng the index weight is determined. Besides, it is simple and convenient in calculation, so, this paper use this method to evaluate cultural creative industry competitiveness.

\section{Research Method \& Model Building}

\subsection{Catastrophe Progression Method}

Catastrophe progression method comes from Catastrophe theory, which was founded in 1972 by a French mathematician, Rene Thom[9]. Firstly, catastrophe progression method adopts multiple levels of contradiction decomposition on evaluation target, then using catastrophe theory and fuzzy mathematics to form a catastrophe fuzzy membership function. Next, through comprehensive quantitative computation to calculate the final total membership function by the normalization formula. Last, it will be the comprehensive evaluation results. In general, after determining the evaluation index, it need to be ranked by importance.

\subsection{Model Building}

\subsubsection{Evaluation Index System}

According to the characteristics of the connotation of cultural creative industry and the theory of competitiveness, this paper construct competitiveness evaluation index system from three aspects, including basic competitiveness, dominant competitiveness and potential competitiveness(table 1).

Table 1 Competitiveness Evaluation Index System of Cultural Creative Industry 


\begin{tabular}{|c|c|c|c|}
\hline Object Level & $\begin{array}{c}\text { First Class } \\
\text { Indicator }\end{array}$ & $\begin{array}{l}\text { Second Class } \\
\text { Indicator }\end{array}$ & Third Class Indicator \\
\hline \multirow{6}{*}{$\begin{array}{l}\text { Competitiveness } \\
\text { of Cultural } \\
\text { Creative } \\
\text { Industry } \\
\text { A }\end{array}$} & $\begin{array}{c}\text { Basic } \\
\text { Competitiveness } \\
\mathbf{B}_{\mathbf{1}}\end{array}$ & $\begin{array}{l}\text { Cultural Resources } \\
\qquad \mathbf{C}_{2}\end{array}$ & $\begin{array}{l}\text { Number of publications issuers } \mathbf{D}_{1} \\
\text { Per } 100,000 \text { population average enrollment in } \\
\text { colleges and universities } \mathbf{D}_{2} \\
\text { Number of Internet users } \mathbf{D}_{3} \\
\text { Population Coverage Rate of TV Programs } \mathbf{D}_{4} \\
\text { Collections of Public Libraries Owned per Person } \\
\mathbf{D}_{5} \\
\text { Performances of Art Performance Troupes } \mathbf{D}_{6} \\
\text { Number of Spectators in Museums }(10000 \text { person- } \\
\text { times) } \mathbf{D}_{7} \\
\text { Number of legal entities } \mathbf{D}_{8}\end{array}$ \\
\hline & $\begin{array}{c}\text { Dominant } \\
\text { Competitiveness }\end{array}$ & $\begin{array}{l}\text { Industry Scale } \\
\mathbf{C}_{3}\end{array}$ & $\begin{array}{l}\text { The proportion of industrial added value to GDP } \\
\text { D9 } \\
\text { Investment in fixed assets } \mathbf{D}_{\mathbf{1 0}}\end{array}$ \\
\hline & \multirow{4}{*}{$\begin{array}{c}\text { Potential } \\
\text { Competitiveness } \\
\mathbf{B}_{3}\end{array}$} & $\begin{array}{l}\text { Economic Benefits } \\
\mathbf{C}_{4}\end{array}$ & $\begin{array}{l}\text { Per capita business revenue } \mathbf{D}_{11} \\
\text { Overall labor productivity } \mathbf{D}_{12} \\
\text { Fixed asset investment rate of return } \mathbf{D}_{13}\end{array}$ \\
\hline & & $\begin{array}{l}\text { Government Policy } \\
\text { C }_{5}\end{array}$ & $\begin{array}{l}\text { Expenditure for culture, sport and media as } \\
\text { percentage of government revenue } \mathbf{D}_{14} \\
\text { Expenditure for education as percentage of } \\
\text { government revenue } \mathbf{D}_{15}\end{array}$ \\
\hline & & $\begin{array}{c}\text { Consumer Demand } \\
\mathbf{C}_{6}\end{array}$ & $\begin{array}{l}\text { Urban households per capital consumption } \\
\text { expenditure on cultural and recreation } \mathbf{D}_{16} \\
\text { Expenditure on cultural and recreation as } \\
\text { percentage of consumption expenditure } \mathbf{D}_{17} \\
\text { Number of patents } \mathbf{D}_{18}\end{array}$ \\
\hline & & $\begin{array}{c}\text { Innovation Ability } \\
\mathbf{C}_{7}\end{array}$ & $\begin{array}{l}\text { R\&D expenses D } 19 \\
\text { Number of Registration of Copyright Contracts } \\
\mathbf{D}_{20}\end{array}$ \\
\hline
\end{tabular}

\subsubsection{Determine the Type of the Catastrophe System}

There are three common types of the catastrophe system which are Cusp Catastrophe, Swallowtail Catastrophe and Butterfly Catastrophe. Their models and normalization formulas are in table $2^{[10]}$.

Table 2 Three Catastrophe Types and Normalization Formula

\begin{tabular}{|c|c|c|c|}
\hline Type & Model & $\begin{array}{l}\text { Control } \\
\text { Variable } \\
\end{array}$ & Normalization Formula \\
\hline $\begin{array}{c}\text { Cusp } \\
\text { Catastrophe }\end{array}$ & $U(X)=X^{4}+A X^{2}+B X$ & A, B & $X_{A}=\sqrt{A}, X_{B}=\sqrt[3]{B}$ \\
\hline $\begin{array}{l}\text { Swallowtail } \\
\text { Catastrophe }\end{array}$ & $U(X)=\frac{1}{5} X^{5}+\frac{1}{3} A X^{3}+\frac{1}{2} B X^{2}+C X$ & $\mathrm{~A}, \mathrm{~B}, \mathrm{C}$ & $\begin{array}{l}X_{A}=\sqrt{A}, X_{B}=\sqrt[3]{B}, \\
X_{C}=\sqrt[4]{C}\end{array}$ \\
\hline $\begin{array}{l}\text { Butterfly } \\
\text { Catastrophe }\end{array}$ & $U(X)=\frac{1}{6} X^{6}+\frac{1}{4} A X^{4}+\frac{1}{3} B X^{3}+\frac{1}{2} C X^{2}+D X$ & $\mathrm{~A}, \mathrm{~B}, \mathrm{C}, \mathrm{D}$ & $\begin{array}{l}X_{A}=\sqrt{A}, X_{B}=\sqrt[3]{B} \\
X_{C}=\sqrt[4]{C}, X_{D}=\sqrt[5]{D}\end{array}$ \\
\hline
\end{tabular}

\subsubsection{Conduct Comprehensive Evaluation by Normalization formula}

Using normalization formula to calculate the $\mathrm{X}$ of each indicator should follow minimax principle and average principle. If the indicators can't instead each other or totally independent, minimax principle should be used. It chooses the smallest one as the $\mathrm{X}$ from $\mathrm{XA}, \mathrm{XB}, \mathrm{XC}$, and $\mathrm{XD}$. And if the indicators can instead each other in some extent or have some relevance with others, average principle should be used. It calculates the average of $\mathrm{XA}, \mathrm{XB}, \mathrm{XC}$, and $\mathrm{XD}$ to be the $\mathrm{X}$.

\section{Evaluation on Cultural creative industry Competitiveness}

This paper selected 11 provinces and cities in east China, and made cultural creative industry as research object. The data source of China Statistical Yearbook on Culture and Related Industries(2015) and China Statistical Yearbook(2015).

\subsection{Data Standardization}

Because each evaluation index is different on the content, dimensions and dimensional units, according to the requirements of mutation progression method, the raw data of the control variables must be converted to $[0,1]$ based on the following formula (1)

$$
Y_{i j}=\frac{X_{i j}-\min X_{i j}}{\max X_{i j}-\min X_{i j}}
$$

$i \nmid 1,2, \mathrm{~L}, 20, j\} 1,2, \mathrm{~L}, 11$, and the standard values of indicators in table 3 .

Table 3 The Standard Values of Indicators

\begin{tabular}{ccccccccccc}
\hline \multirow{2}{*}{ Region } & \multicolumn{8}{c}{ Indicator } \\
\cline { 2 - 10 } & $\mathbf{D}_{\mathbf{1}}$ & $\mathbf{D}_{\mathbf{2}}$ & $\mathbf{D}_{\mathbf{3}}$ & $\mathbf{D}_{\mathbf{4}}$ & $\mathbf{\mathbf { D } _ { \mathbf { 5 } }}$ & $\mathbf{D}_{\mathbf{6}}$ & $\mathbf{D}_{\mathbf{7}}$ & $\mathbf{D}_{\mathbf{8}}$ & $\mathbf{D}_{\mathbf{9}}$ & $\mathbf{D}_{\mathbf{1 0}}$ \\
\hline Beijing & 0.6565 & 1.0000 & 0.1707 & 1.0000 & 0.2691 & 0.0873 & 0.0495 & 0.8789 & 1.0000 & 0.0325 \\
Tianjin & 0.1258 & 0.6560 & 0.0704 & 1.0000 & 0.2764 & 0.0075 & 0.1116 & 0.1760 & 0.6505 & 0.1191 \\
Hebei & 0.4868 & 0.0000 & 0.4635 & 0.8444 & 0.0000 & 0.3919 & 0.3393 & 0.2739 & 0.2080 & 0.5402 \\
Liaoning & 0.4006 & 0.2507 & 0.3145 & 0.7778 & 0.1891 & 0.0347 & 0.1445 & 0.2417 & 0.0000 & 0.3502 \\
Shandong & 0.5424 & 0.0970 & 0.6137 & 0.6667 & 0.0618 & 0.8977 & 0.6768 & 0.6319 & 0.1986 & 1.0000 \\
Shanghai & 0.5249 & 0.3753 & 0.1886 & 1.0000 & 1.0000 & 0.1058 & 0.2628 & 0.3705 & 0.3930 & 0.0434 \\
Jiangsu & 1.0000 & 0.2282 & 0.5613 & 0.9778 & 0.1818 & 0.3069 & 1.0000 & 0.8762 & 0.2890 & 0.9176 \\
Zhejiang & 0.7975 & 0.0931 & 0.4424 & 0.9333 & 0.2655 & 1.0000 & 0.5756 & 0.8612 & 0.3478 & 0.3759 \\
Fujian & 0.2651 & 0.12466 & 0.2986 & 0.7111 & 0.1491 & 0.5705 & 0.3124 & 0.3056 & 0.2182 & 0.2804 \\
Guangdong & 0.7104 & 0.0775 & 1.0000 & 0.9778 & 0.1455 & 0.2156 & 0.5610 & 1.0000 & 0.3299 & 0.4403 \\
Hainan & 0.0000 & 0.0657 & 0.0000 & 0.0000 & 0.0618 & 0.0000 & 0.0000 & 0.0000 & 0.1168 & 0.0000 \\
\hline
\end{tabular}

\begin{tabular}{|c|c|c|c|c|c|c|c|c|c|c|}
\hline \multirow{2}{*}{ Region } & \multicolumn{10}{|c|}{ Indicator } \\
\hline & $\mathbf{D}_{11}$ & $D_{12}$ & $D_{13}$ & $\mathbf{D}_{14}$ & $D_{15}$ & $D_{16}$ & $D_{17}$ & $\mathrm{D}_{18}$ & $D_{19}$ & $\mathbf{D}_{20}$ \\
\hline Beijing & 0.5839 & 0.6142 & 1.0000 & 1.0000 & 0.5322 & 1.0000 & 0.6265 & 0.3682 & 0.0339 & 1.0000 \\
\hline Tianjin & 0.4697 & 1. 0000 & 0.1671 & 0.0000 & 0.7122 & 0.2086 & 0.1507 & 0.1247 & 0.2540 & 0.0587 \\
\hline Hebei & 0.0515 & 0.8184 & 0.0000 & 0.0549 & 0.7895 & 0.0000 & 0.2434 & 0.0934 & 0.0376 & 0.0076 \\
\hline Liaoning & 0.0027 & 0.0725 & 0.0038 & 0.0831 & 0.0000 & 0.3388 & 0.8011 & 0.0903 & 0.0719 & 0.0214 \\
\hline Shandong & 0.4349 & 0.2808 & 0.0553 & 0.0614 & 1. 0000 & 0.0881 & 0.0000 & 0.3589 & 0.8278 & 0.0395 \\
\hline Shanghai & 1.0000 & 0.3114 & 0.7891 & 0.0484 & 0.2637 & 0.9971 & 0.5997 & 0.2464 & 0.1791 & 0.1467 \\
\hline Jiangsu & 0.1558 & 0.1396 & 0.1082 & 0.3022 & 0.6932 & 0.6176 & 1. 0000 & 1.0000 & 0.8881 & 0.1789 \\
\hline Zhejia & 0.2034 & 0.3419 & 0.2648 & 0.2936 & 0.9557 & 0.5206 & 0.2203 & 0.9421 & 0.4317 & 0.0543 \\
\hline Fujia & 0.0000 & 0.0851 & 0.0731 & 0.1434 & 0.8622 & 0.2863 & 0.4558 & 0.1827 & 0.2175 & 0.0000 \\
\hline Guangdong & 0.0369 & 0.0000 & 0.2625 & 0.0906 & 0.9300 & 0.4341 & 0.7342 & 0.8988 & 1. 0000 & 0.0185 \\
\hline Hainan & 0.1283 & 0.4070 & 0.0272 & 0.2437 & 0.6525 & 0.1589 & 0.7947 & 0.0000 & 0.0000 & 0.0154 \\
\hline
\end{tabular}

\subsection{Comprehensive Evaluation}

According to the basic principle of catastrophe progression method and catastrophe type, this paper carried out the evaluation on cultural creativity industry competitiveness for all regions. Take Beijing as an example, the process and result of the evaluation in table 4.

Table 4 The Process and Result of Comprehensive Evaluation (Beijing)

\begin{tabular}{|c|c|c|c|c|c|c|}
\hline \multirow{2}{*}{$\frac{\text { Type }}{\text { Butterfly }}$} & \multicolumn{4}{|c|}{ Normalization Value } & \multirow{3}{*}{$\frac{\text { Principle }}{\text { Minimax }}$} & \multirow{2}{*}{$\frac{\text { Result }}{\mathrm{C} 1}$} \\
\hline & $\mathrm{X}_{\mathrm{D} 1}$ & $\mathrm{X}_{\mathrm{D} 2}$ & $\mathrm{X}_{\mathrm{D} 3}$ & $\mathrm{X}_{\mathrm{D} 4}$ & & \\
\hline Catastrophe & 0.8102 & 1.0000 & 0.6428 & 1.0000 & & \\
\hline Swallowtail & $\mathrm{X}_{\mathrm{D} 5}$ & $\mathrm{X}_{\mathrm{D} 6}$ & $\mathrm{X}_{\mathrm{D} 7}$ & & & \\
\hline Catastrophe & 0.5187 & 0.4436 & 0.4717 & & Minimax & 0.4436 \\
\hline Swallowtail & $\mathrm{X}_{\mathrm{DS}}$ & $\mathrm{X}_{\mathrm{D} 9}$ & $\mathrm{X}_{\mathrm{D} 10}$ & & & $\mathrm{C} 3$ \\
\hline Catastrophe & 0.9375 & 1.0000 & 0.4247 & & Average & 0.7874 \\
\hline Swallowtail & $\mathrm{X}_{\mathrm{D} 11}$ & $\begin{array}{l}\mathrm{X}_{\mathrm{D} 12} \\
\mathrm{C}^{2}\end{array}$ & $\mathrm{X}_{\mathrm{D} 13}$ & & & $\mathrm{C} 4$ \\
\hline Catastrophe & 0.7641 & 0.8500 & 1.0000 & & Average & 0.8714 \\
\hline Cusp & $\mathrm{X}_{\mathrm{D} 14}$ & $\mathrm{X}_{\mathrm{D} 15}$ & & & & $\mathrm{C} 5$ \\
\hline Catastrophe & 1.0000 & 0.8104 & & & Average & 0.9052 \\
\hline Cusp & $\mathrm{X}_{\mathrm{D} 16}$ & $\mathrm{X}_{\mathrm{D} 17}$ & & & & C6 \\
\hline Catastrophe & 1.0000 & 0.8557 & & & Average & 0.9278 \\
\hline Swallowtail & $\mathrm{X}_{\mathrm{D} 18}$ & $\mathrm{X}_{\mathrm{D} 19}$ & $\mathrm{X}_{\mathrm{D} 20}$ & & & $\mathrm{C} 7$ \\
\hline Catastrophe & 0.6068 & 0.3238 & 1.0000 & & Average & 0.6435 \\
\hline Cusp & $\mathrm{X}_{\mathrm{Cl}}$ & $\mathrm{X}_{\mathrm{C} 2}$ & & & & B1 \\
\hline Catastrophe & 0.8017 & 0.7627 & & & Average & 0.7822 \\
\hline & $\mathrm{X}_{\mathrm{C} 3}$ & $\mathrm{X}_{C 4}$ & & & & B2 \\
\hline Catastrophe & 0.8873 & 0.9551 & & & Average & 0.9212 \\
\hline Swallowtail & $\begin{array}{l}.0013 \\
\mathrm{X}_{\mathrm{CS}}\end{array}$ & $\mathrm{X}_{\mathrm{C} 6}$ & $\mathrm{X}_{\mathrm{C} 7}$ & & & B3 \\
\hline Catastrophe & 0.9514 & 0.9753 & 0.8957 & & Average & 0.9408 \\
\hline Swallowtail & $\mathrm{X}_{\mathrm{BI}}$ & $\mathrm{X}_{\mathrm{B} 2}$ & $\mathrm{X}_{\mathrm{B} 3}$ & & & A \\
\hline Catastrophe & 0.8884 & 0.9730 & 0.9849 & & Average & 0.9474 \\
\hline
\end{tabular}

With the same method and calculation process can get the score of 7 second class indicators of other provinces and cities, and these regions are ranked by the score (table 5). Similarly, it also can get the score and rank of three competitiveness in first class indicator, until it is concluded that the total score and rank of regional cultural creative industry competitiveness(table 6).

\begin{tabular}{|c|c|c|c|c|c|c|c|c|c|c|c|c|c|c|}
\hline \multirow[b]{2}{*}{ Region } & \multicolumn{2}{|c|}{$\mathrm{C}_{1}$} & \multicolumn{2}{|c|}{$\mathrm{C}_{2}$} & \multicolumn{2}{|c|}{$\mathrm{C}_{3}$} & \multicolumn{2}{|c|}{$\mathrm{C}_{4}$} & \multicolumn{2}{|c|}{$\mathrm{C}_{5}$} & \multicolumn{2}{|c|}{$\mathrm{C}_{6}$} & \multicolumn{2}{|l|}{$\mathrm{C}_{7}$} \\
\hline & Score & $\begin{array}{l}\text { Ra } \\
\text { nk }\end{array}$ & Score & $\begin{array}{l}\text { Ra } \\
\text { nk }\end{array}$ & Score & $\begin{array}{l}\text { Ra } \\
\text { nk }\end{array}$ & Score & $\begin{array}{l}\text { Ra } \\
\text { nk } \\
\end{array}$ & Score & $\begin{array}{l}\mathrm{Ra} \\
\mathrm{nk} \\
\end{array}$ & Score & $\begin{array}{l}\text { Ra } \\
\text { nk }\end{array}$ & Score & $\begin{array}{l}\mathrm{Ra} \\
\mathrm{nk}\end{array}$ \\
\hline Beijing & 0.6428 & 2 & 0.4436 & 3 & 0.7874 & 5 & 0.8714 & 2 & 0.9052 & 1 & 0.9278 & 1 & 0.6435 & 5 \\
\hline Tianjin & 0.3546 & 9 & 0.1959 & 9 & 0.6245 & 8 & 0.7749 & 3 & 0.4465 & 9 & 0.4944 & 9 & 0.4929 & 7 \\
\hline Hebei & 0.0000 & 10 & 0.0000 & 10 & 0.6577 & 6 & 0.3874 & 8 & 0.5793 & 8 & 0.3122 & 10 & 0.3118 & 10 \\
\hline Liaoning & 0.6305 & 3 & 0.3261 & 7 & 0.4203 & 10 & 0.2390 & 11 & 0.1442 & 11 & 0.7554 & 5 & 0.3663 & 8 \\
\hline Shandong & 0.4594 & 6 & 0.2486 & 8 & 0.7928 & 4 & 0.5998 & 5 & 0.6239 & 7 & 0.1484 & 11 & 0.6613 & 4 \\
\hline Shanghai & 0.6590 & 1 & 0.4729 & 2 & 0.5992 & 9 & 0.8734 & 1 & 0.4307 & 10 & 0.9209 & 2 & 0.5596 & 6 \\
\hline Jiangsu & 0.6111 & 4 & 0.4264 & 4 & 0.8586 & 1 & 0.4957 & 7 & 0.7174 & 3 & 0.8929 & 3 & 0.8705 & 1 \\
\hline Zhejiang & 0.4532 & 7 & 0.5152 & 1 & 0.8048 & 3 & 0.6226 & 4 & 0.7635 & 2 & 0.6627 & 6 & 0.7364 & 3 \\
\hline Fujian & 0.4994 & 5 & 0.3861 & 5 & 0.6275 & 7 & 0.3199 & 9 & 0.6652 & 5 & 0.6524 & 8 & 0.3430 & 9 \\
\hline Guangdong & 0.4263 & 8 & 0.3814 & 6 & 0.8352 & 2 & 0.3026 & 10 & 0.6385 & 6 & 0.7805 & 4 & 0.7723 & 2 \\
\hline Hainan & 0.0000 & 10 & 0.0000 & 10 & 0.1629 & 11 & 0.5018 & 6 & 0.6805 & 4 & 0.6625 & 7 & 0.1175 & 11 \\
\hline \multicolumn{15}{|c|}{ Table 6 The Score of 3 Competitiveness } \\
\hline & \multicolumn{4}{|c|}{$\mathbf{B}_{1}$} & \multicolumn{2}{|c|}{$\mathbf{B}_{2}$} & & \multicolumn{3}{|c|}{$\mathbf{B}_{3}$} & \multicolumn{4}{|c|}{$\mathbf{A}$} \\
\hline Region & Score & & Rank & & Score & Ran & & Score & & Rank & & ore & $\mathrm{Ra}$ & \\
\hline Beijing & 0.782 & & 2 & & 0.9212 & 1 & & 0.9408 & & 1 & & 9474 & 1 & \\
\hline Tianjin & 0.588 & & 9 & & 0.8 & 0 & & 0.76 & & 7 & & 8837 & 8 & \\
\hline Hebei & 0.000 & & 10 & & 0.7700 & 8 & & 0.7289 & & 10 & & 6135 & 15 & \\
\hline Liaoning & 0.7 & & 4 & & 0.63 & 10 & & 0.6895 & & 11 & & 8771 & & \\
\hline Shandong & 0.653 & & 8 & & 0.8669 & 3 & & 0.7404 & & 9 & & 8965 & & \\
\hline Shanghai & 0.79 & & 1 & & 0.8650 & 4 & & 0.8314 & & 5 & & 9332 & & \\
\hline Jiangsu & 0.767 & & 3 & & 0.8590 & 5 & & 0.9253 & & 2 & & 9358 & & \\
\hline Zhejiang & 0.737 & & 5 & & 0.8755 & 2 & & 0.8907 & & 3 & & 9289 & 4 & \\
\hline Fujian & 0.717 & & 6 & & 0.7381 & 9 & & 0.8161 & & 6 & & 9004 & 6 & \\
\hline Guangdong & 0.689 & & 7 & & 0.7926 & 7 & & 0.8858 & & 4 & & 9086 & 5 & \\
\hline Hainan & 0.000 & & 10 & & 0.5991 & 11 & & 0.7607 & & 8 & & 5923 & 1 & 1 \\
\hline
\end{tabular}

\subsection{Result and Suggestions}

In order to more intuitively observe the competitiveness of cultural creative industry in 11 provinces and cities, on the basis of the above tables, this paper constructed a radar map about The level of regional cultural creative industry competitiveness in 2014(figure 1).Meanwhile it used SPSS 22.0 to have on K-Means Cluster Analysis, the result is the classification of competitiveness level, as shown in table 7. With the result of this evaluation, the competitiveness level of cultural creative industry in east China is high, but it still has gap between different regions. The 11 provinces and cities were divided into 3 classes by cluster analysis, class I are Beijing, Shanghai, Jiangsu, and Zhejiang, these regions have a better competitiveness. Class II are Guangdong, Fujian, Shandong, Tianjin, and Liaoning, these regions also have a good competitiveness, and it do not have a large gap between class I. Class III are Hebei and Hainan, compared with class I and class II, there are still large gaps to fill. 


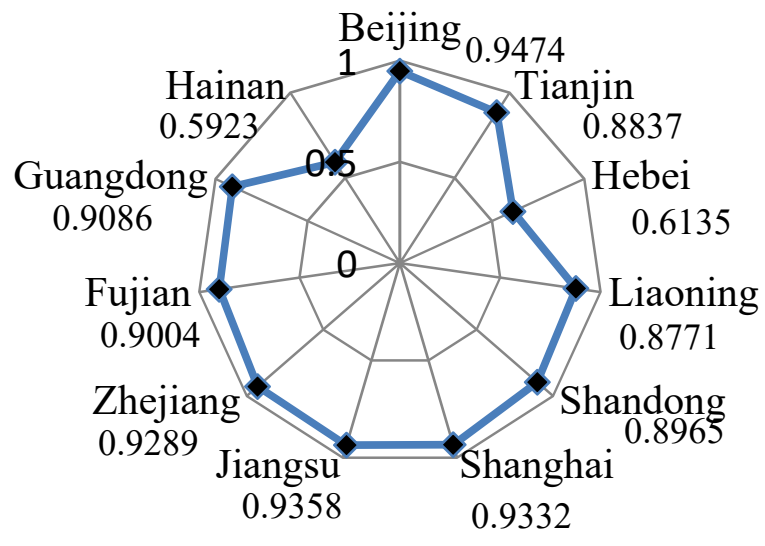

Figure 1 The Level of Regional Cultural Creative Industry Competitiveness in 2014

\begin{tabular}{cccc}
\multicolumn{4}{c}{ Table 7 The Classification of Competitiveness Level } \\
\hline Class & Cluster center & Number & Region \\
\hline I & 0.9363 & 4 & Beijing, Shanghai, Jiangsu, Zhejiang \\
II & 0.8933 & 5 & Guangdong, Fujian, Shandong, Tianjin, Liaoning \\
III & 0.6029 & 2 & Hebei, Hainan \\
\hline
\end{tabular}

Combined with table 5 and table 6 ,it analyzed the status quo further more. Jiangsu overcome Shanghai on the score, because Jiangsu has advantages in industry scale and innovation ability. Meanwhile Shanghai should enhance fiscal expenditure on cultural and educational entertainment. Guangdong is fifth, though its industry scale is huge, the economic benefits are not good. So, it should strengthen in industrial transformation and upgrading. As for regions after Guangdong, especially Hebei and Hainan, their most index score is not high, and there would be much to do. Firstly, government should increase investment to promote industrial scale. Secondly, it must pay more attention to talents, funds and innovation ability. Thirdly, government should play an important role in support and guide. Finally, it is vital to strengthen cooperation and communication in various areas, because it could promote mutual learning.

\section{Conclusion}

Based on the theory of competitiveness and the catastrophe progression method, this paper construct the competitiveness evaluation index system of regional cultural creative industry, including basic competitiveness, dominant competitiveness and potential competitiveness. Based on the cross section data of 2014, it empirically evaluate the competitiveness of cultural creative industry of 11 provinces and cities in east China, and then rank their order by the score. The results shows that the competitiveness level of cultural creative industry in these areas is high, but it still has gap between different regions. Although the results are valuable, the paper is still inadequacy due to some limits. For example, in the future, it should collect more data with much long period to show the trends.

\section{References}

[1] W. Zhang, Y.H. Xie, A Study on the Cultural and Creative Industry Competitiveness of Guangzhou: Compared with Shanghai and Shenzhen, Forward Position in Economics. Vol.3(5)(2012) 62-72.

[2] J. Hua, The connotation, structure and strategic focus of cultural industry competitiveness, Journal of Peking University(Humanities and Social Sciences). Vol.42(2) (2005) 9-16.

[3] N.H. Gu, J.C. Xia, A Comparison of Cultural Industry Competitiveness among Some Important Cities in China, Journal of Business Economics. Vol.194(12) (2007) 52-57.

[4] L.J. Ye, L. Li, The evaluation and analysis of differences on regional cultural industry competitiveness in China, Science and Technology Manament Research. Vol.29(3) (2009) 94-97.

[5] J. He, Research on the Evaluation System of Cultural and Creative Industries Competition, Jilin University(2011).

[6] B.L. Kang, Y.J. Chen, Study on Construction of Competitiveness Evaluation Index System of City Culture Creative Industries and its Application--taking Shanghai, Hangzhou and Nanjing as Examples, Journal of Hubei Polytechnic University (Humanities and Social Sciences). Vol.1(2014) 37-41.

[7] X.Y. Gao, C.X Shao, Evaluation and Countermeasure Analysis on the Competitiveness of Regional Cultural and Creative Industry, Enterprise Economy(2013). 